\title{
Individual Tree Crown Detection Using UAV Orthomosaic
}

\author{
Khairul Nizam Tahar \\ Centre of Studies for Surveying Science \\ and Geomatics, Faculty of Architecture, \\ Planning and Surveying \\ Universiti Teknologi MARA \\ Shah Alam, Malaysia \\ khairu10127@uitm.edu.my
}

\section{Nafisah Khalid}

Centre of Studies for Surveying Science and Geomatics, Faculty of Architecture, Planning and Surveying Universiti Teknologi MARA Shah Alam, Malaysia nafisahkhalid@uitm.edu.my

\author{
Mimie Asmida Asmadin \\ Centre of Studies for Surveying Science \\ and Geomatics, Faculty of Architecture, \\ Planning and Surveying \\ Universiti Teknologi MARA \\ Shah Alam, Malaysia \\ advancedphotogrammetry@gmail.com
}

Ahmad Norhisyam Idris

Centre of Studies for Surveying Science and Geomatics, Faculty of Architecture, Planning and Surveying

Universiti Teknologi MARA

Shah Alam, Malaysia

ahmad_nurhisyam@uitm.edu.my

\author{
Saiful Aman Hj Sulaiman \\ Centre of Studies for Surveying Science \\ and Geomatics, Faculty of Architecture, \\ Planning and Surveying \\ Universiti Teknologi MARA \\ Shah Alam, Malaysia \\ saifulaman@uitm.edu.my \\ Mohammad Hezri Razali \\ Centre of Studies for Surveying Science \\ and Geomatics, Faculty of Architecture, \\ Planning and Surveying \\ Universiti Teknologi MARA \\ Shah Alam, Malaysia \\ hezrirazali@uitm.edu.my
}

\begin{abstract}
Unmanned Aerial Vehicles (UAVs) are increasingly used in forestry as they are economical and flexible. This study aims to present the advantages of the drone photogrammetry method in collecting individual tree crowns, as individual tree crown detection could deliver essential ecological and economic information. The referred accuracy for individual tree crown extraction is $79.2 \%$. Only crowns that were clearly visible were selected and manually delineated on the image because the distribution of the true crown size is significantly different from the segmented crowns. The aim of this study is to investigate UAVs orthomosaics in individual tree crown detection. The objectives of this study are to produce the orthomosaic of tree crown extraction mapping using the Pix4D software and analyze the tree crowns using tree crown delineation and the OBIA algorithm. Data processing involves the processing of aerial images using Pix4Dmapper. Automatic tree crown detection involves a tree crown delineation algorithm and OBIA operations to process the tree crown extraction. The crown delineation algorithm and OBIA algorithm operation will be compared to the actual tree crown measurement in terms of diameter and area. The tree crown delineation method obtained a $0.347 \mathrm{~m}$ mean diameter difference from the actual tree crown diameter, while the OBIA approach obtained $4.98 \mathrm{~m}$. The tree crown delineation method obtained $97.26 \%$ of the actual tree crown area, while OBIA obtained $91.74 \%$.
\end{abstract}

Keywords-orthomosaic; unmanned aerial vehicle; digital surface model; digital terrain model; tree crown

\section{INTRODUCTION}

Individual tree crown extraction parameters deliver essential ecological and economic information to decision makers [1]. The accurate extraction of the tree crown is a necessary precondition to derive tree position and dimensions such as height, width, and volume. A tree crown is a distinct object with a strong spectral variability $[5,6]$. Tree crown can be defined as the top part of the tree which features branches that grow out from the main trunk and support the whole leaves. Tree crown is essential as it strongly links with other tree parameters that are used to estimate the growing stock [2]. Tree crowns can be divided into four classes, namely dominant, codominant, intermediate, and overtopped. Dominant crowns extend above the general level of the canopy. They are the largest and fullest crowns in the stand as they receive full light from above and some light from the sides [3]. Codominant crowns make up the general level of the canopy [4]. They are shorter than the dominant crowns and they receive direct light from above but little or no light from the sides. Intermediate crowns occupy a subordinate position in the canopy. They are narrow in position and shorter than dominant and codominant crowns. They receive some direct light from above but no light from the sides. Overtopped crowns are below the general level of the canopy.

This study presents the advantages of the drone photogrammetry method in collecting individual tree crowns. Unmanned Aerial Vehicles (UAVs) have been increasingly used in forestry as they are economical and flexible. A UAV can be defined as an aircraft that can navigate without a human pilot on board or can fly autonomously through softwarecontrolled flight plans. To take measurements from photographs, a camera is mounted on the UAV and pointed vertically towards the ground. The output of UAV photogrammetry is typically a map or 3D model of a real-world object [7]. Many products can be extracted by aerial imagery, 
including surface models, orthophotos, 3D building models, contour maps, and volumetric surveys [8]. A drone-based technique for topographic analysis has better accuracy than satellite remote sensing, which has limited resolution and quality depending on various factors, resulting in discontinuities in obtaining correct land information. UAVderived photogrammetric data are relatively more sensitive, cheaper, and more productive than data from other platforms such as airborne LIDAR systems [9].

Orthomosaic mapping has been used in many commercial sectors such as surveying, mining, construction, and agriculture for its precise measurement and calculations [10, 11]. Orthomosaics are very useful for analyzing the features of a large plot or area of land. An orthomosaic can be divided into two parts, i.e. ortho and mosaic. Ortho is defined as straightening and mosaic is defined as piecing things together $[12,13]$. The orthomosaic allows the drones to take many photos from above and stitch these images together into a single scene. To stitch these images together, every photograph must be ortho- and geo-rectified in terms of lens distortion, camera tilt perspective, etc. In other words, an orthomosaic can be defined as an aerial image of an area that is composed of multiple photographs stitched together using photogrammetry, which has been scaled and geographically corrected for accuracy $[14,15]$. Generally, orthomosaic derives a much bigger resolution and detail compared to satellite imagery. The automatic individual tree crown delineation in a highly diverse tropical forest using WorldView22 satellite is presented in [16, 17]. The method works in successive steps that involve preprocessing, selection of forested pixels, enhancement of borders, detection of pixels in the crown's borders, correction of shade in large trees, and finally, segmentation of the tree crowns. These methods are done in hierarchical stages to produce accurate individual tree crown delineation. The reported accuracy in individual tree crown extraction is $79.2 \%$. Only crowns that are clearly visible are selected and manually delineated on the image. Authors in $[18,19]$ identified false positives and false negatives of tree crown extraction. False positives identified a crown where there was no crown, and false negatives did not identify a crown where there was a true crown. This situation happened as the true crown size distribution was significantly different from the segmented crowns. This approach overestimated the size of small crowns, when it was less than $5 \mathrm{~m}$.

In the current study, the UAV-based photogrammetric approach is used in individual tree crown extraction as aerial photos have proved useful in the efficient conservation and management of forest inventory. A drone-based approach can provide a more accurate result compared to satellite images. The image quality in terms of spectral and radiometric resolution can help produce tree crown inspection more accurately. The aim of this study is to investigate UAV orthomosaic in individual tree crown detection.

\section{MATERIALS AND METHODS}

The objectives of this study are to detect tree crowns using a crown delineation algorithm and analyze the individual tree crown result with the actual tree crown. The preliminary study is the initial exploration of tree crown extraction that involves review and research. A preliminary study involves designing the problem statement, aims, and objectives. Data collection involves the fieldwork observation to extract the tree crown. After data collection, the data will be processed using the necessary software, then, the results are analyzed to determine the accuracy of the outcome. Figure 1 illustrates the workflow of this study in detail.

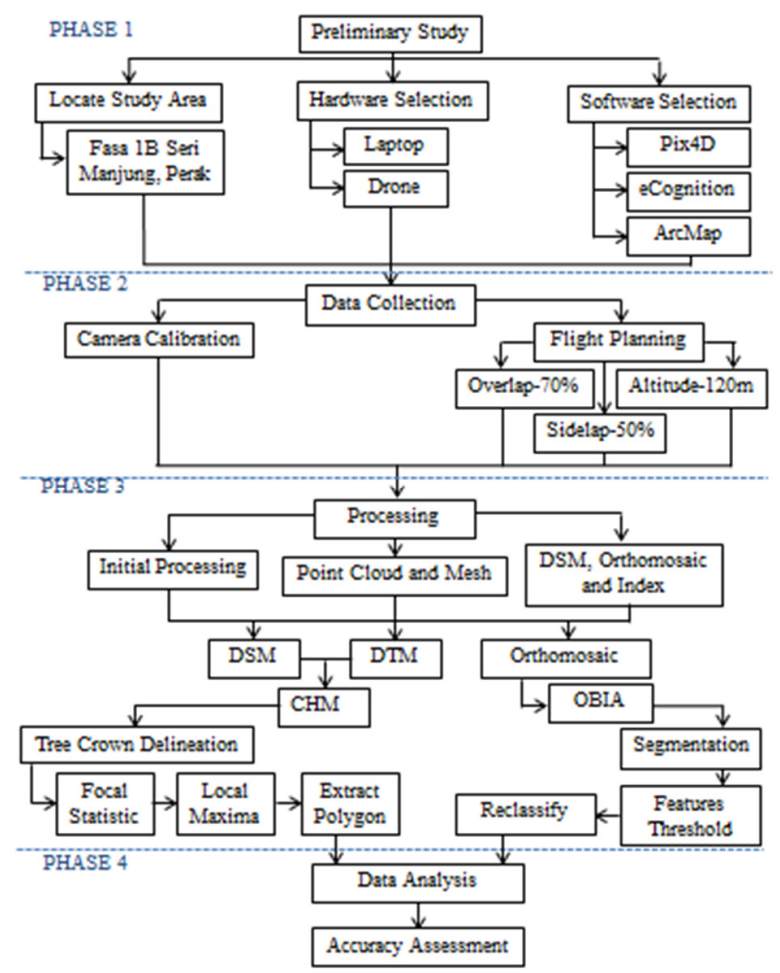

Fig. 1. Research methodology.

The study area is located in Fasa 1b Seri Manjung, Perak, Malaysia. The coordinates of the survey area are $4^{\circ} 12^{\prime} 12.14^{\prime \prime} \mathrm{N}$ and $100^{\circ} 40^{\prime} 21.41$ "E. The study area covers 54.6243 acres. The selection of the study area focused on the area that contains trees. The types of trees in the study area were not a concern as tree crown detection can be done on any kind of tree.

\section{A. Flight Planning}

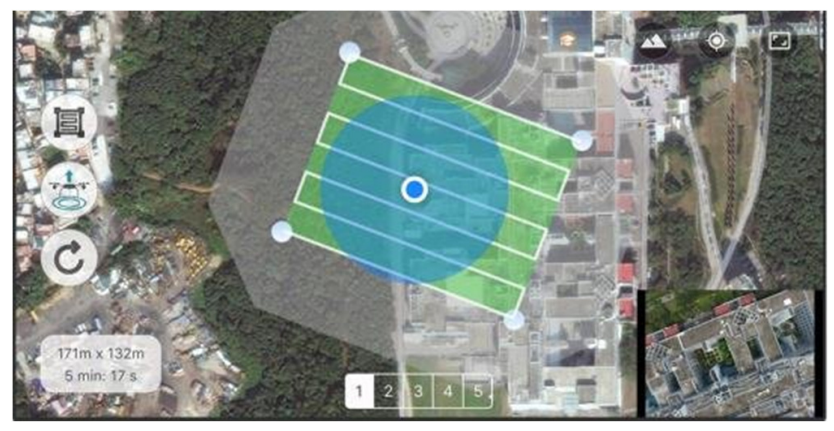

Fig. 2. Flight route planning in Altizure. 
For flight planning, altitude, overlap, and side lap should be considered. The altitude in this flight planning was $120 \mathrm{~m}$. The overlap was $70 \%$, with a side lap of approximately $50 \%$. The software used in designing the flight plan during data collection is Altizure. The application automatically generates the fly paths over the study area. The capturing of data is designed for generating a 2D orthomosaic as it captures vertical photographs (Figure 2).

\section{B. Image Processing}

In Pix4Dmapper, the initial processing includes computing keypoints on the images. The keypoints will then be used to find matches between the images. This initial processing also allows the software to run an automatic aerial triangulation and bundle block adjustment. After that, point cloud and mesh take place. This processing option allows the setting of parameters for point cloud densification. The image scale was set to half image size, and multiscale was checked to compute additional $3 \mathrm{D}$ points on multiple image scales. The point density chosen was "optimal". For the minimum number of matches, the default value "3" was chosen to allow each $3 \mathrm{D}$ point to correctly re-project at least three images. The final process is the Digital Surface Model (DSM), the orthomosaic, and the index operation. The processing options allow changes of the desired outputs for DSM and orthomosaic generation to be made. For this step, DSM and orthomosaics are automatically generated. Canopy Height Model (CHM) represents the height between the ground and the top of the object above the ground. The CHM is used for automatic tree crown detection. The CHM is generated by subtracting the DTM from the DSM.

\section{Tree Crown Delineation Algorithm}

The tree crown delineation algorithm was implemented on ArcMap software. The tools involved in the automatic tree crown detection processing are the focal statistics tool, the raster calculator, the slope tool, and the export polygon operation. To generate local maxima, the focal statistics tool should be used first. The focal statistics tool performs a neighborhood process that calculates an output raster where the value for each output cell is a function of the values of all the input cells that are in a specified neighborhood around that location. In the window, CHM was the input raster. The neighborhood chosen had a "rectangle" shape, with a neighborhood setting of $3 \times 3$ (height $\times$ width). The option selected for statistic type was "mean". Local maxima are individual pixels that represent high surfaces. To compute local maxima, focal statistics were needed. The local maxima operation was operated using a raster calculator. The slope operation allows the creation of a tree crown outline. This operation involves $\mathrm{CHM}$ as the input raster. The extracted tree crown will then be converted to polygon.

\section{Object-Based Image Analysis Algorithm Technique}

Object-Based Image Analysis (OBIA) is the most accurate relevant technique. OBIA produces higher accuracy than pixelto-pixel analysis. The OBIA technique used in this research is multiresolution segmentation. The segmented orthomosaic was then used for thresholding features indices and classification in order to detect tree crowns. This algorithm allowed the identification of one pixel size for single image objects. It also merged them with neighboring pixels based on relative homogeneity. For this research, multiresolution segmentation was performed against red, green, blue, and near-infra-red bands. The scale parameter was set to 90 and the image layer weight for near-infra-red was set to 2. For shape and compactness, the value was set at 0.3 and 0.7 respectively. The thresholding features indices used were NDVI and NPV. NDVI threshold was performed for tree detection, while NPV threshold was performed for non-tree detection. The arithmetic threshold for NDVI involved the near-infra-red and red bands, while NPV involved green and blue bands. Reclassification of tree and non-tree indices was performed next. Classification was performed to discriminate tree from non-tree features. The classification was performed using the assign class tool. For tree classification, the condition of thresholding was set at NDVI $>0.08$ for tree and NPV $>0$ and for non-tree.

\section{RESULTS AND DISCUSSION}

Aerial image processing was conducted to generate the orthomosaic. The orthomosaic generation was conducted with the Pix4D software. There were three main processing stages, namely initial processing, point cloud and mesh, and DSM, orthomosaic and index. The orthomosaic was generated for individual tree crown detection analysis. Figure 3(a) shows the orthomosaic mapping of Fasa 1B Seri Manjung, Perak. Orthomosaic products are free from any distortion and can be used for true measurement [20]. Figure 3(b) shows the DSM and Figure 3(c) shows the Digital Terrain Model (DTM) of the study area. The DSM includes all objects like buildings, trees, and cars to generate the earth's surface. DTM, on the other hand, excludes all objects on the earth's surface and represents the bare earth.

\section{A. Tree Crown Delineation (TCD)}

The CHM represents the height between the ground and the top of the objects above it. Figure 4(a) shows the CHM model on the orthomosaic. The CHM can be generated by substracting the DTM from the DSM. In Figure 4(a), the white cell indicates trees in the CHM model that are located along the road. Figure 4(b) shows the output of the focal statistics operation which was used for generating the local maxima. The focal statistics tool performs a neighborhood process that calculates an output raster where the value for each output cell is a function of the values of all the input cells that are in a specified neighborhood around that location. In Figure 4(b), the white cell shows tree features along the road. Local maxima are individual pixels that represent high surfaces. Local maxima were computed to find the tree tops. The output of the local maxima was then converted into points. Figure 4(c) shows the local maxima output and converted points. Figure 5(a) shows the tree crown outline after the extraction process using tree crown delineation algorithm. The results were obtained from the CHM model as input raster using the slope tool. The tree crown is outlined in red. It can be seen that the outlined tree crown is along the road side. In Figure 5(b), the left image shows the result of tree crown extraction using slope operation. The right image shows the tree crown outline overlays with the orthomosaic at $40 \%$ transparency. Figure 5(c) shows the final result for this approach on the orthomosaic. The tree crowns can be seen in red line. 
(a)
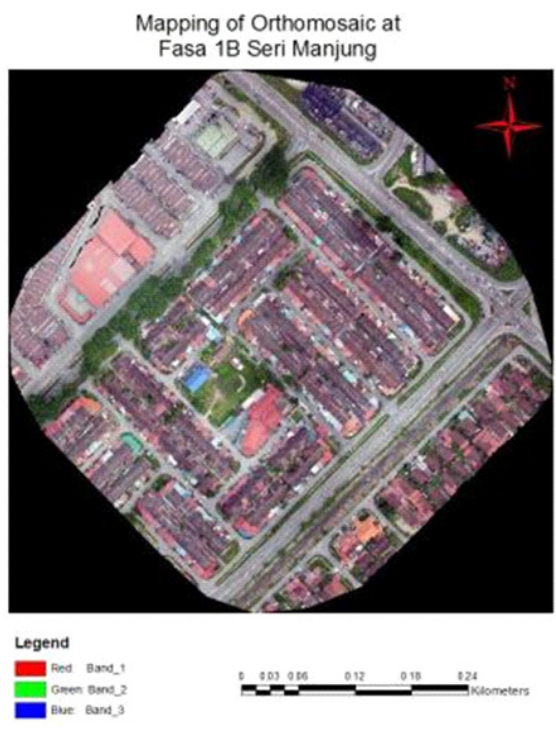

DSM of Fasa 18 Seri Manjung

(b)

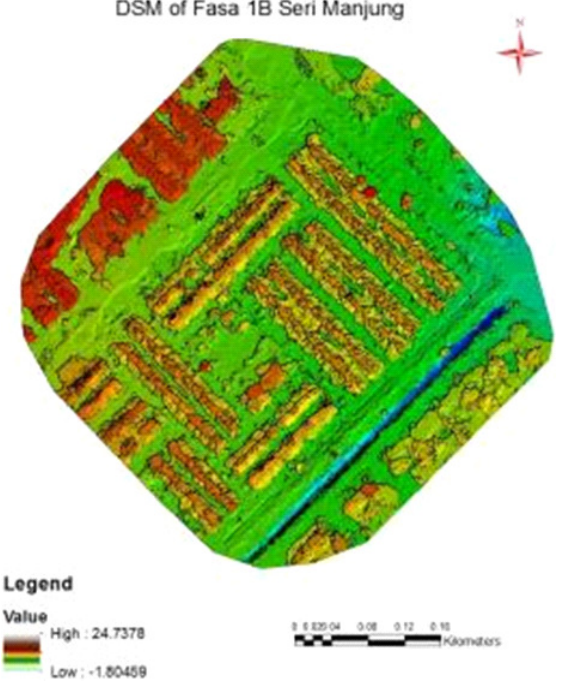

DTM of Fasa 1B Seri Manjung

(c)

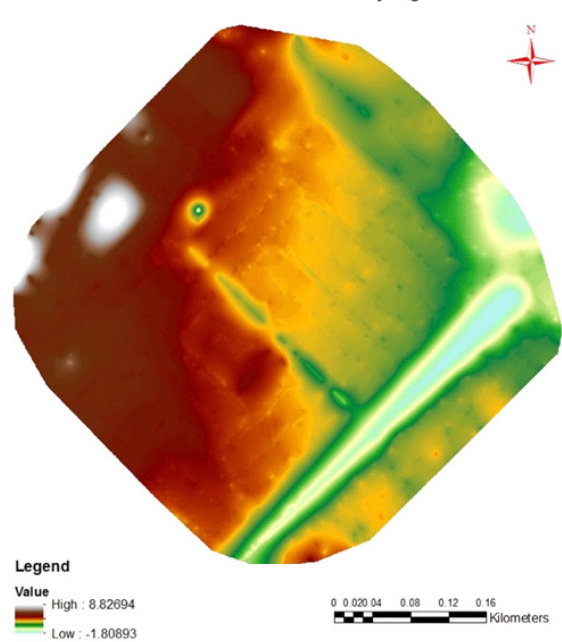

(a)

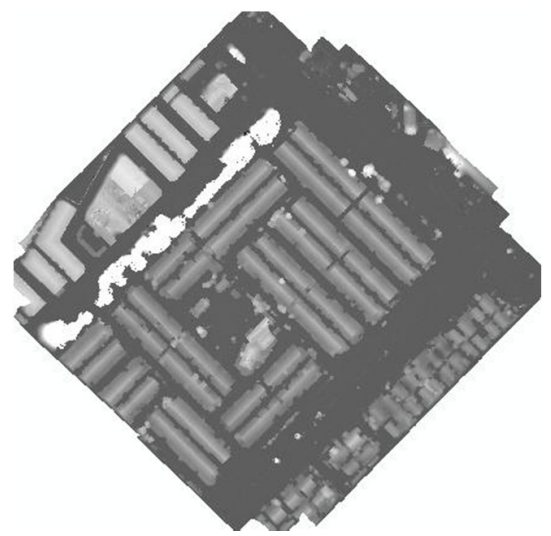

(b)
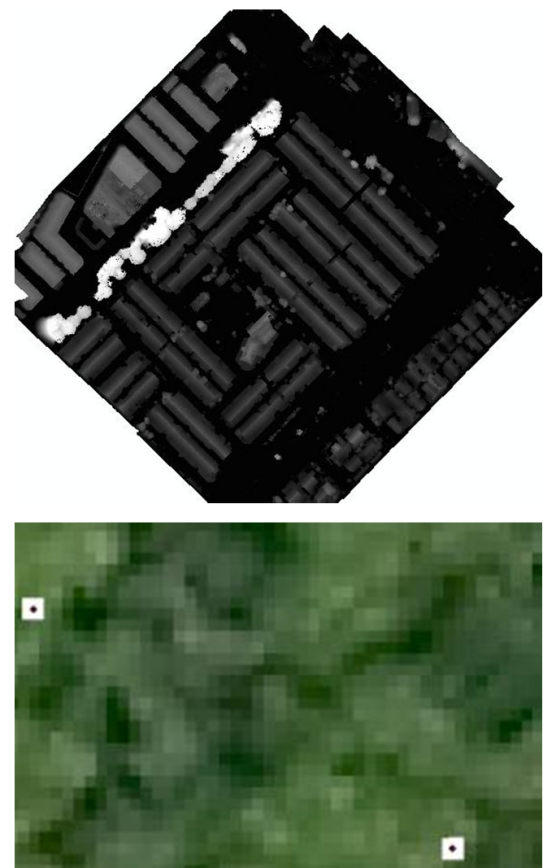

Fig. 4. TCD results. (a) CHM model, (b) focal statistic, (c) converted local maxima in points (right).

\section{B. Object-Based Image Analysis Algorithm}

Multiresolution segmentation operation could turn each pixel segmented into single image objects. Figure 6 shows the result of the multiresolution operation. The operation approached the scale parameter at 90 with shape and compactness of 0.3 and 0.7 respectively. The thresholding feature indices involved two features indices, which are NDVI and NPV (Figure 7(a)). NDVI indices are used for tree detection while NPV indices are used for non-tree detection. Both indices are computed to discriminate trees from non-trees. The threshold of NDVI was set at $>0.08$ for tree detection, and the threshold of NPV was set at $>0$ for non-tree detection. In Figure 7(b), the detected trees can be seen as green lines, and detected non-trees as red lines. From the final result, it can be said that NDVI indices are not suitable for this process as they detect other green areas like grass despite extracting only trees.

Fig. 3. Results. (a) Orthomosaic, (b) DSM, (c) DTM. 
(a)

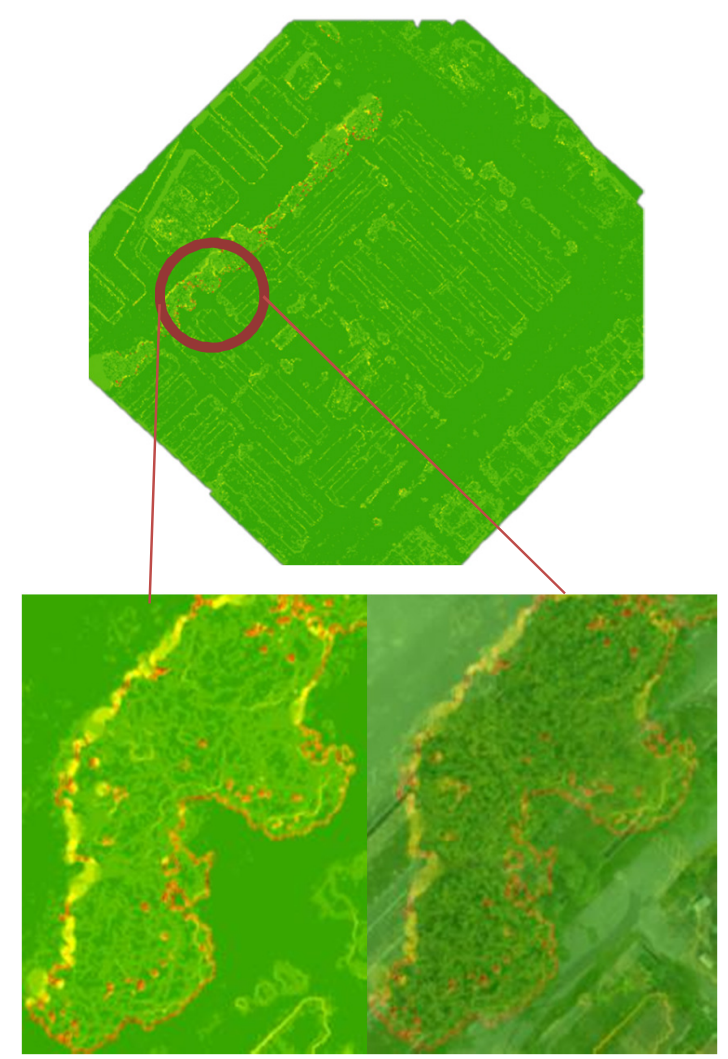

(c)

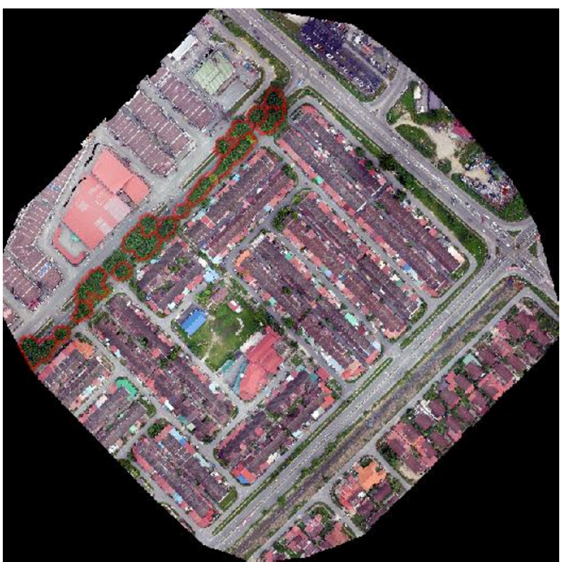

Fig. 5. Crown results. (a) Tree crown outline, (b) tree crown outline (left) and tree crown outline overlay with orthomosaic (right), (c) final tree crown delineation overlay with the orthomosaic.

The final result of the OBIA method is affected by a few conditions. Yhe classification of tree and non-tree is affected by the thresholding features indices, which are NDVI and NPV (Figure 7(c)). Both thresholds are suitable as both detect features into their own classes, which are tree and non-tree. The scale parameter during segmentation operation also affects the final result. The scale parameter should be set below 90 as the scale parameter value affects the object classification.

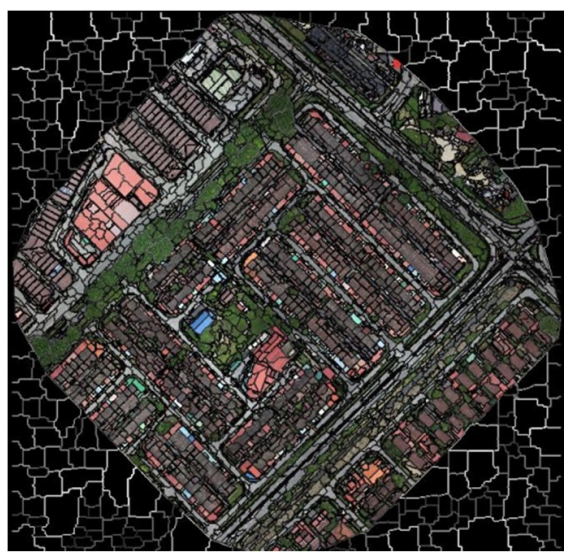

Fig. 6. The result of multiresolution segmentation.

(a)

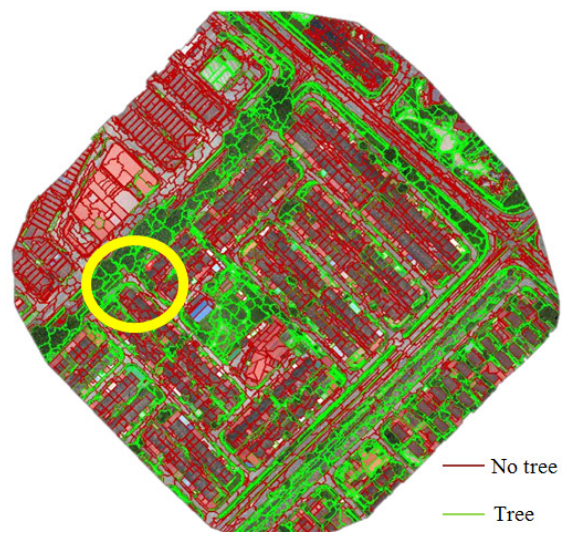

(b)
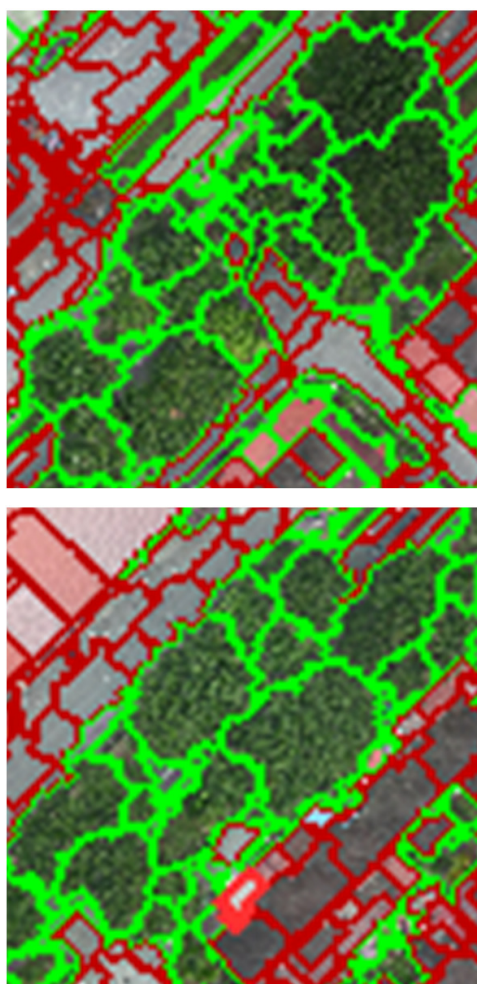

Fig. 7. OBIA result. (a) Thresholding, (b) reclassification, (c) final result. 


\section{Accuracy Assessment}

\section{1) Diameter Assessment}

Accuracy assessment operation involves analyzing the comparison between the actual tree crown, the tree crown delineation algorithm approach, and the OBIA algorithm approach in terms of diameter and area. The comparison was conducted based on ten samples. The comparison results were then converted into a line graph. In Figure 8(a), the tree crown delineation method shows small differences of actual tree crown diameter compared to the OBIA approach, which shows big differences from the actual tree crown diameter. All the 10 samples of the TCD method in red lines are closer to the actual tree crown diameter measurement in blue lines compared to the OBIA method in green lines.

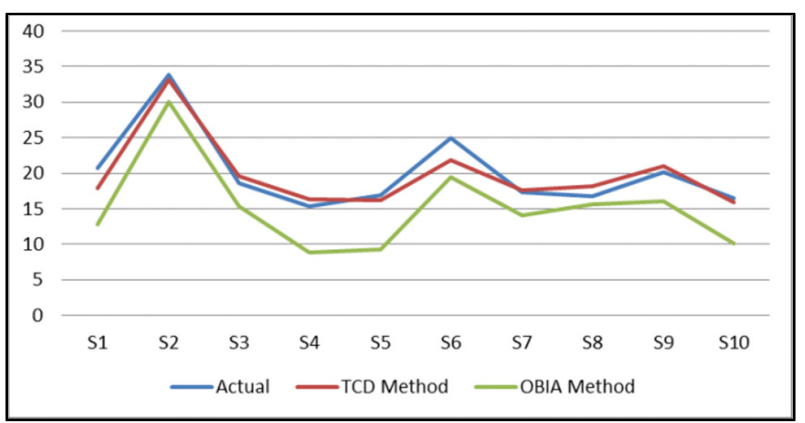

(a)

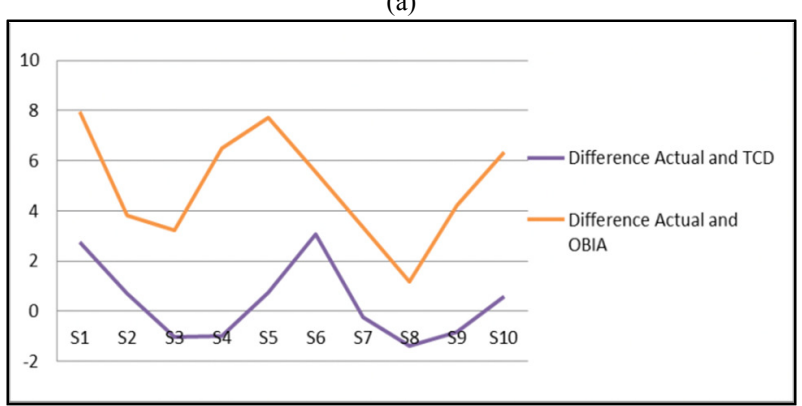

(b)

Fig. 8. Tree crown diameter. (a) Measurements of actual, tree crown delineation, and OBIA, (b) difference between actual and tree crown delineation and actual and OBIA.

Figure 8(b) shows the tree crown diameter comparison between the actual tree crown with TCD method and the actual tree crown with the OBIA method. The difference in diameter between the actual tree crown and the TCD method had a mean value of $0.347 \mathrm{~m}$ over 10 tree samples, while the OBIA method obtained a mean value of $4.98 \mathrm{~m}$. The difference between the actual tree crown and TCD in purple lines is not big. The difference between the actual crown and the OBIA method is slightly bigger.

\section{2) Area Assessment}

Figure 9(a) shows the small differences from the actual tree crown area compared to the OBIA approach. It can be seen that the TCD method is close to the actual tree crown. Figure 9(b) shows the comparison between the actual tree crown with the TCD method and between the actual tree crown with the OBIA method. The TCD and the OBIA methods obtained the 97.25\% and the $91.74 \%$ of the tree crown area respectively. The difference between the actual crown and the TCD is not big. The difference between the actual crown and the OBIA method is bigger.

(a)

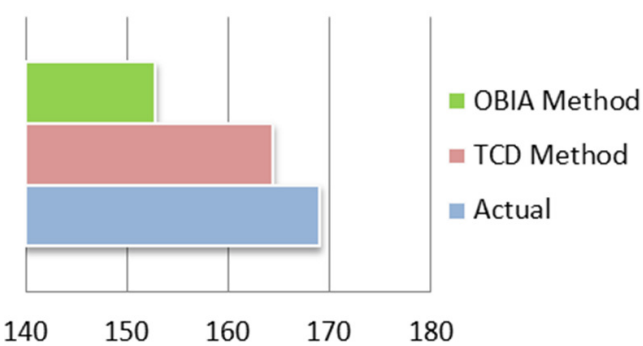

(b)

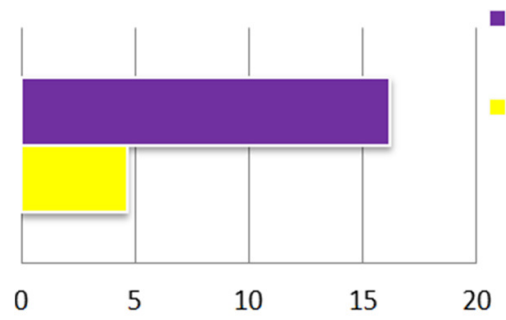

Actual-OBIA difference

Actual-TCD difference

Fig. 9. Tree crown area. (a) Measurements of actual, tree crown delineation, and OBIA, (b) comparison.

This study has almost similar results with previous relevant studies. Authors in [21] correctly classified $95 \%$ of individual trees, authors in [22] also successfully detect $90 \%$ of individual trees using fuzzy system, and authors in [23] used the deep learning approach to detect individual trees and the result of tree detection was about $90 \%$. Therefore, the results achieved in this study have an improvement of about $2.25 \%$ by using the TCD method.

\section{Conclusions}

The differences between the actual crown and the TCD and OBIA results are affected due to a few conditions in terms of diameter and area measurements. The tree crown measurement differences may be due to the number of overlapping images. Based on the aerial image processing, the trees along the road are located under less than five overlapping images. This may affect the results of the tree crown diameter and area measurements between the actual crown, the TCD method, and the OBIA method. The process of an automatic tree crown that uses two different software may also affect the final result of both methods compared to the actual tree crown measurement. The OBIA method result may be due to the scale parameter value during segmentation operation.

\section{ACKNOWLEDGMENT}

Faculty of Architecture, Planning, and Surveying Universiti Teknologi MARA (UiTM), Research Management Institute (RMi) and Ministry of Higher Education (MOHE) are greatly acknowledged for providing the fund BESTARI 600RMC/DANA 5/3/BESTARI (TD) (006/2019). 


\section{REFERENCES}

[1] S. Krause, T. Sanders, J.-P. Mund, and K. Greve, "UAV-Based Photogrammetric Tree Height Measurement for Intensive Forest Monitoring," Remote Sensing, vol. 11, no. 7, Mar. 2019, Art. no. 758, https://doi.org/10.3390/rs1 1070758.

[2] M. Immitzer, F. Vuolo, and C. Atzberger, "First Experience with Sentinel-2 Data for Crop and Tree Species Classifications in Central Europe," Remote Sensing, vol. 8, no. 3, Mar. 2016, Art. no. 166, https://doi.org/10.3390/rs8030166.

[3] A. Rajput, A. Hussain, F. Akhtar, Z. H. Khand, and H. Magsi, "A Versatile Decentralized 3D Volumetric Fusion for On-line Reconstruction," Engineering, Technology \& Applied Science Research, vol. 10 , no. 6, pp. 6584-6588, Dec. 2020, https://doi.org/10.48084/ etasr.3838.

[4] S. Baena, J. Moat, O. Whaley, and D. S. Boyd, "Identifying species from the air: UAVs and the very high resolution challenge for plant conservation," PLOS ONE, vol. 12, no. 11, 2017, Art. no. e0188714, https://doi.org/10.1371/journal.pone.0188714.

[5] J. Maschler, C. Atzberger, and M. Immitzer, "Individual Tree Crown Segmentation and Classification of 13 Tree Species Using Airborne Hyperspectral Data," Remote Sensing, vol. 10, no. 8, Aug. 2018, Art. no. 1218, https://doi.org/10.3390/rs10081218.

[6] C. Torresan et al., "Forestry applications of UAVs in Europe: a review," International Journal of Remote Sensing, vol. 38, no. 8-10, pp. 24272447, May 2017, https://doi.org/10.1080/01431161.2016.1252477.

[7] S. S. Abdullah, K. N. Tahar, M. F. A. Rashid, and M. A. Osoman, "Capabilities of UAV-Based Watershed Segmentation Method for Estimating Tree Crown: A Case Study of Oil Palm Tree," IOP Conference Series: Earth and Environmental Science, vol. 385, Nov. 2019, Art. no. 012015, https://doi.org/10.1088/1755-1315/385/1/012015.

[8] N. Liba and J. Berg-Jürgens, "Accuracy of Orthomosaic Generated by Different Methods in Example of UAV Platform MUST Q," IOP Conference Series: Materials Science and Engineering, vol. 96, Nov. 2015, Art. no. 012041, https://doi.org/10.1088/1757-899X/96/1/012041.

[9] A. Grznárová, M. Mokroš, P. Surový, M. Slavík, M. Pondelík, and J. Merganič, "The Crown Diameter Estimation from Fixed Wing Type of Uav Imagery," ISPRS - International Archives of the Photogrammetry, Remote Sensing and Spatial Information Sciences, vol. 4213, pp. 337341, Jun. 2019, https://doi.org/10.5194/isprs-archives-XLII-2-W13-3372019.

[10] F. Bayat, H. Arefi, and F. Alidoost, "Individual Tree Detection and Determination of Tree Parameters Using Uav-Based LIDAR Data," ISPRS - International Archives of the Photogrammetry, Remote Sensing and Spatial Information Sciences, vol. 4218, pp. 179-182, Oct. 2019, https://doi.org/10.5194/isprs-archives-XLII-4-W18-179-2019.

[11] H. Yao, R. Qin, and X. Chen, "Unmanned Aerial Vehicle for Remote Sensing Applications-A Review," Remote Sensing, vol. 11, no. 12, p. 1443, Jan. 2019, https://doi.org/10.3390/rs11121443.

[12] C. Suwanprasit, J. Strobl, and J. Adamczyk, "Extraction of Complex Plantations from VHR Imagery using OBIA Techniques," International Journal of Geoinformatics, vol. 11, no. 1, pp. 73-83, Mar. 2015.

[13] S. H. Adil, M. Ebrahim, S. S. A. Ali, and K. Raza, "Performance Analysis of Duplicate Record Detection Techniques," Engineering, Technology \& Applied Science Research, vol. 9, no. 5, pp. 4755-4758, Oct. 2019, https://doi.org/10.48084/etasr.3036.

[14] M. Kamal, S. Phinn, and K. Johansen, "Object-Based Approach for Multi-Scale Mangrove Composition Mapping Using Multi-Resolution Image Datasets," Remote Sensing, vol. 7, no. 4, pp. 4753-4783, Apr. 2015, https://doi.org/10.3390/rs70404753.

[15] Z. Zhang, A. Kazakova, L. M. Moskal, and D. M. Styers, "Object-Based Tree Species Classification in Urban Ecosystems Using LiDAR and Hyperspectral Data," Forests, vol. 7, no. 6, Jun. 2016, Art. no. 122, https://doi.org/10.3390/f7060122.

[16] M. Brach, J. Chan, and P. Szymański, "Accuracy assessment of different photogrammetric software for processing data from low-cost UAV platforms in forest conditions," iForest - Biogeosciences and Forestry, vol. 12, no. 5, pp. 435-441, Sep. 2019, https://doi.org/10.3832/ifor2986012 .
[17] F. H. Wagner et al., "Individual tree crown delineation in a highly diverse tropical forest using very high resolution satellite images," ISPRS Journal of Photogrammetry and Remote Sensing, vol. 145, pp. 362-377, Nov. 2018, https://doi.org/10.1016/j.isprsjprs.2018.09.013.

[18] K. Johansen, T. Raharjo, and M. McCabe, "Using Multi-Spectral UAV Imagery to Extract Tree Crop Structural Properties and Assess Pruning Effects," Remote Sensing, vol. 10, no. 6, Jun. 2018, Art. no. 854, https://doi.org/10.3390/rs10060854.

[19] Z. Zhen, L. Quackenbush, and L. Zhang, "Trends in Automatic Individual Tree Crown Detection and Delineation-Evolution of LiDAR Data," Remote Sensing, vol. 8, no. 4, Apr. 2016, Art. no. 333, https://doi.org/10.3390/rs8040333.

[20] N. Che Mat and K. N. Tahar, "Surf Zone Mapping Using Multirotor Unmanned Aerial Vehicle Imagery," International Journal of Optics, vol. 2019, May 2019, Art. no. e2987301, https://doi.org/10.1155/ $2019 / 2987301$.

[21] J. Holmgren and Å. Persson, "Identifying species of individual trees using airborne laser scanner," Remote Sensing of Environment, vol. 90, no. 4, pp. 415-423, Apr. 2004, https://doi.org/10.1016/S0034-4257(03) 00140-8.

[22] M. A. A. Khameneh, "Tree Detection and Species Identification using LiDAR Data," M. S. thesis, Royal Institute of Technology, Stockholm, Sweden, 2013.

[23] A.-I. Pleșoianu, M.-S. Stupariu, I. Șandric, I. Pătru-Stupariu, and L. Drăguț, "Individual Tree-Crown Detection and Species Classification in Very High-Resolution Remote Sensing Imagery Using a Deep Learning Ensemble Model," Remote Sensing, vol. 12, no. 15, Jan. 2020, Art. no. 2426, https://doi.org/10.3390/rs12152426.

\section{AUTHORS PROFILE}

Mimie Asmida Asmadin is a graduate student in the Centre of Studies for Surveying Science and Geomatics, Univesiti Teknologi MARA (UiTM), Malaysia. His research interests include Unmanned Aerial Vehicle (UAV) for mapping, photogrammetry and modeling.

Khairul Nizam Tahar is the Head of the Centre of Studies for Surveying Science and Geomatics, Faculty of Architecture, Planning and Surveying, UiTM, Malaysia. His major research interests include photogrammetry and close range photogrammetry especially on UAV applications. He has published 1 book, 1 book chapter, and over 70 articles in journals and conference proceedings. In the last 5 years, he received a number of research grants from the University and the Ministry. He has been appointed as the chief editor and an editorial board member of several international journals. $\mathrm{He}$ is also a keynote and invited speaker at national and international conferences and short courses.

Saiful Aman Hj Sulaiman is a Senior Lecturer at the Centre of Studies for Surveying Science and Geomatics, Faculty of Architecture, Planning and Surveying, UiTM, Malaysia. His major research interests include GNSS, geodesy, cadastra, and surveying.

Nafisah Khalid is a Senior Lecturer at the Centre of Studies for Surveying Science and Geomatics, Faculty of Architecture, Planning and Surveying, UiTM, Malaysia. His major research interests include LiDAR, remote sensing, and geospatial.

Ahmad Norhisyam Idris is a Lecturer at the Centre of Studies for Surveying Science and Geomatics, Faculty of Architecture, Planning and Surveying, UiTM, Malaysia. His major research interests include GNSS, geodesy, and surveying.

Mohammad Hezri Razali is a Lecturer at the Centre of Studies for Surveying Science and Geomatics, Faculty of Architecture, Planning and Surveying, UiTM, Malaysia. His major research interests include cadastra, surveying, and ground penetrating radars. 